\title{
Aspectos epidemiológicos da neoplasia mamária canina
}

\author{
Epidemiological aspects of canine mammary tumor \\ Luciana Oliveira de Oliveira ${ }^{1}$, Rosemari Teresinha de Oliveira ${ }^{2}$, Alexandre Paulino Loretti ${ }^{2}$, \\ Rafael Rodrigues ${ }^{3} \&$ David Driemeier ${ }^{2}$
}

\begin{abstract}
RESUMO
Tumor de mama é a neoplasia mais freqüente em cadelas, entretanto, há controvérsias sobre os fatores que influenciam o desenvolvimento do tumor. O objetivo deste trabalho foi estudar o perfil das cadelas com tumor de mama atendidas no Hospital de Clínicas Veterinárias da Universidade Federal do Rio Grande do Sul (HCV-UFRGS). Foram coletados os dados de 85 cadelas apresentando neoplasias mamárias, entre junho de 1999 e maio de 2000. Foram analisados o tempo de evolução dos tumores, neoplasias anteriores, histórico reprodutivo, localização, tamanho dos nódulos, ulcerações, metástases pulmonares e resultados da histopatologia. A partir destes dados, $71,8 \%$ foram lesões malignas e, $28,2 \%$, benignas. A maioria dos malignos foi de carcinomas e, dos benignos, adenoma. A idade média foi de 9 anos para as cadelas com tumores benignos e de 9 anos para os malignos. O progestágeno foi associado a um maior número de tumores benignos. As pseudocieses foram relacionadas a tumores de mama malignos. Tanto o uso de progestágenos como as pseudocieses foram relacionados com o aparecimento precoce de neoplasias mamárias em cadelas.
\end{abstract}

Descritores: tumor, mama, cães, pseudocieses, progestágenos.

\begin{abstract}
Mammary tumor is the most frequent neoplasm occurring in bitches. Factors that exert influences on mammary neoplasms are still controversial. The purpose of this study was to analyze data from 85 dogs admitted for treatment at the Veterinary Hospital of Universidade Federal do Rio Grande do Sul (HCV-UFRGS) between July 1999 and May 2000. Period of development of the tumor, previous tumors, reproductive history, location and size of the lesions, ulceration of the tumoral masses, presence of lung metastases and histopathology data were analyzed. According to histopathology, $71.8 \%$ of the animals presented malignant tumors and $28.2 \%$ showed benign tumors. Carcinoma was the most common malignant mammary tumor and adenoma was the most frequent benign tumor. The use of progestins was related to a higher percentage of benign tumoral masses and the pseudopregnancies were associated with development of malignant neoplasms. The average age of the animals was 9 years for benign tumors and 10.2 for malignant ones. The use of progestagens and the development of pseudopregnancies were both associated with earlier development of canine mammary tumors.
\end{abstract}

Key words: tumor, mammary, dogs, pseudopregnancies, progestagens. 


\section{INTRODUÇÃO}

As neoplasias mamárias correspondem a cerca de $50 \%$ dos tumores das cadelas. São detectados em animais de meia idade a velhos, sem predisposição racial $[1,7,13]$.

A transformação neoplásica é multifatorial [12]. O desenvolvimento de neoplasia mamária na cadela é dependente, em grande parte, de hormônios. A incidência de tumor de mama é de $0,5 \%$ com a castração antes do primeiro cio, $8 \%$ após o primeiro ciclo estral e $26 \%$ após dois ou mais ciclos, até os dois primeiros anos [7,14].

Cerca de $50 \%$ dos tumores mamários de cadelas são malignos $[1,6,13,14]$, com uma variação de 36 [9] a 91,4\% [8] de malignidade. Entre os malignos, a maioria é de carcinomas [1,5,6,12-14]. O tipo histológico é o principal fator no prognóstico para os tumores de mama [11,13,14].

Entre as cadelas com tumor de mama benigno, $26 \%$ desenvolvem, mais tarde, tumor em outra glândula [12]. Cadelas com vários nódulos podem apresentar tumores benignos e malignos concomitantemente [7,10-13].

As pseudocieses aumentam a chance de desenvolvimento de tumor de mama [2].

O uso de anticoncepcionais à base de progestágenos tem sido associado com um pequeno aumento de tumores de mama $[2,10]$.

Apesar de nos tumores de mama em cadelas serem mais freqüentes as neoplasias, existem controvérsias sobre os fatores que influenciam o seu desenvolvimento. Este é o primeiro comunicado sobre os tumores de mama em cadelas no sul do Brasil.

O objetivo deste trabalho foi estudar o perfil das cadelas com tumores de mama atendidas na rotina do Hospital de Clínicas Veterinárias da Universidade Federal do Rio Grande do Sul (HCV-UFRGS).

\section{MATERIAIS E MÉTODOS}

Procurou-se identificar os tipos de tumor de mama apresentados pelos animais atendidos no HCVUFRGS e analisar os fatores que podem influenciar as neoplasias mamárias, incluindo idade, aspectos reprodutivos dos pacientes, tamanho dos nódulos, glândulas envolvidas, exames histopatológicos e radiológicos.
Foram coletados e analisados os dados de 85 cadelas, portadoras de tumor de mama, atendidas no HCV-UFRGS entre junho de 1999 e maio de 2000. Foram excluídos da pesquisa os pacientes com história prévia de neoplasias e aqueles cujas fichas clínicocirúrgicas apresentavam informações incompletas.

Os proprietários foram questionados sobre o tempo de evolução dos tumores, neoplasias anteriores, se o animal foi castrado, uso de anticoncepcionais, número de partos e pseudocieses. Após exame clínico, foi registrada a localização, o tamanho dos tumores e a presença de ulceração. Foram feitas radiografias torácicas para verificar se haviam metástases.

As mamas coletadas foram fixadas em formalina a $10 \%$ e encaminhadas ao Setor de Patologia da Faculdade de Veterinária da Universidade Federal do Rio Grande do Sul para exame histopatológico. O material fixado foi clivado e submetido ao processamento usual para inclusão em parafina, sendo realizados cortes de 4 a 5 micrômetros em micrótomo rotativo e corado por Hematoxilina-Eosina [15].

\section{RESULTADOS}

Foram coletados e analisados os dados referentes a 85 cadelas apresentando neoplasias mamárias. Destas, $71,8 \%$ (61) foram neoplasias malignas e, $28,2 \%$ (24), benignas. Os resultados dos exames histopatológicos dos tumores são mostrados na Tabela 1 .

Entre as biópsias realizadas, 25,9\% foram carcinomas (22 casos), 16,5\% adenocarcinomas (14), 2,3\% cistoadenocarcinomas (2), 22,3\% tumores mistos malignos (19), 4,7\% fibrossarcomas (4), 11,8\% adenomas (10), 5,9\% cistoadenomas (5), 9,4\% tumores mistos benignos (8) e 1,2\% mioepitelioma benigno (1).

Mais de um tipo histológico de tumor foi identificado em $25,9 \%$ das cadelas. $8,2 \%$ dos animais tiveram tumores benigno e maligno ao mesmo tempo. Para estes animais, consideramos o diagnóstico de tumor maligno.

A média de idade das cadelas com tumores benignos foi de $9( \pm 3,1)$ anos e, tumores malignos, de $10,2( \pm 2,5)$ anos. As idades variaram de 3 a 16 anos. O intervalo entre aparecimento do tumor, visualizado pelo proprietário, e a apresentação do paciente no HCV-UFRGS, foi de 9,5 ( $\pm 12,1)$ meses. Corrigindose a média das idades em relação a este intervalo de 
tempo, a idade média das cadelas diminui para 8,5 anos para os tumores benignos e, 9,6, para os malignos.

As neoplasias compreendidas nas três mamas craniais corresponderam a 5,9\% dos casos, enquanto nas três mamas caudais corresponderam a $51,8 \%$. Tumores em todas as mamas ocorreram em 36,5\% dos casos. A terceira mama esteve envolvida isoladamente em 5,9\% dos casos. Nódulos tumorais múltiplos foram identificados em $77,6 \%$ das cadelas analisadas. A presença de tumores nas duas cadeias mamárias correspondeu a 55,3\% da casuística.

Os tumores que apresentaram diâmetro máximo menor que $5 \mathrm{~cm}$ corresponderam a $34,5 \%$ dos casos; os entre 5 e $10 \mathrm{~cm}$ a $44,2 \%$ dos casos; entre 11 e $15 \mathrm{~cm}$ a $17,2 \%$ dos casos, e os maiores que $15 \mathrm{~cm}$ a $3,5 \%$ dos casos.

Entre os tumores ulcerados, $72,7 \%$ corresponderam a tumores malignos.

A administração prévia de progestágenos foi relatada em $44,4 \%$ das cadelas com tumor de mama. $23,8 \%$ das cadelas com tumor de mama receberam mais que três doses de hormônios. O uso de progestágenos foi relacionada a uma maior porcentagem de tumores benignos $(42,1 \%)$. Para as cadelas com tumores benignos e que receberam progestágenos, a média de idade foi de 8,6 anos. Entre as cadelas com tumor benigno que nunca receberam progestágenos, a média de idade foi de 9,7 anos.

Pseudocieses foram observadas em $48 \%$ das cadelas com tumores de mama. Destas, $72,3 \%$ tiveram tumores malignos. A média de idade para as cadelas com pseudociese e tumor de mama benigno foi 8,8 anos e 9,1 anos para o maligno. As cadelas que nunca desenvolveram pseudociese apresentaram tumor de mama benigno com idade média de 9,6 anos, e 10,3 anos para os malignos.

Quanto ao número de partos, $48 \%$ das cadelas com tumor de mama foram nulíparas. Entre as cadelas que tiveram gestações, $48,7 \%$ foram multíparas.

Metástases torácicas foram diagnosticadas em $15,9 \%$ dos tumores malignos. Todas as metástases observadas foram referentes a tumores malignos.

\section{DISCUSSÃO}

A média de 50\% de malignidade relatada pela maioria dos autores $[1,7,13,14]$ foi menor do que a média encontrada no presente trabalho. Entretanto, taxas mais altas também já foram relatadas. A demora na apresentação dos pacientes no hospital pode ser responsável pela maior malignidade, pois tumores benignos podem vir a se tornar malignos [8]. A grande heterogeneidade histológica torna difícil o estabelecimento de um sistema de classificação universal para os tumores de mama em caninos, tornando complicada a comparação de resultados entre dados de diferentes pesquisadores $[6,13]$. Ainda não está determinado o papel das células basais epiteliais e mioepiteliais na histogênese de tumores complexos, mistos e carcinomas, podendo haver participação de uma (tumores simples) ou de ambas (tumores complexos) populações de células no processo de transformação neoplásica nos cães [4,11].

A média das idades das cadelas com tumores malignos ficou dentro da relatada na literatura. Para os tumores benignos, a média foi mais baixa.

Em trabalho realizado na área metropolitana de Tóquio, $60 \%$ dos casos de tumor de mama em cães apresentaram menos que $3 \mathrm{~cm}$ de diâmetro [17]. No presente trabalho, não foi observada a mesma preocupação, por parte dos proprietários, em tratar os animais precocemente.

O intervalo entre a identificação do tumor, pelo proprietário, e a apresentação do paciente no HCVUFRGS para diagnóstico e tratamento foi muito grande. Vários proprietários relataram ter observado o tumor há anos e buscaram atendimento apenas após crescimento excessivo ou ulceração da lesão. O diagnóstico e tratamento precoce dos tumores de mama proporcionariam um melhor prognóstico para os pacientes. Talvez caiba à classe veterinária a responsabilidade sobre um melhor esclarecimento à população.

A maioria dos tumores malignos foi composta pelos carcinomas, estando de acordo com a literatura [1,5,6,8,9,12-14,17]. Entre os tumores benignos, os cistoadenomas e os adenomas foram os mais comuns. Segundo diferentes autores, os adenomas [8] ou os tumores mistos [5,9] prevaleceram entre os tumores benignos.

Uma pequena porcentagem de cadelas com tumores malignos apresentaram, ao mesmo tempo, tumores benignos em outras mamas, como também é relatado na literatura [8]. 
Tabela 1. Histopatologia e número de casos dos tumores de mama em cadelas atendidas no Hospital de Clínicas Veterinárias (HCV) UFRGS entre junho de 1999 e maio de 2000.

\begin{tabular}{|c|c|c|c|}
\hline \multicolumn{3}{|c|}{ Histopatologia } & \multirow{2}{*}{$\begin{array}{c}\begin{array}{c}\text { No de } \\
\text { casos }\end{array} \\
1\end{array}$} \\
\hline Malignos & Carcinoma & Simples & \\
\hline & & Complexo & 6 \\
\hline & & Tubular & 6 \\
\hline & & Epidermóide & 3 \\
\hline & & Anaplásico & 3 \\
\hline & & Lobular & 1 \\
\hline & & Sólido & 1 \\
\hline & & Esquirroso & 1 \\
\hline & Adenocarcinoma & Simples & 12 \\
\hline & & Tubular & 1 \\
\hline & & Papilífero & 1 \\
\hline & Cistoadenocarcinoma & Papilífero & 2 \\
\hline & Misto Maligno & & 19 \\
\hline & Fibrosarcoma & & 4 \\
\hline \multirow[t]{7}{*}{ Benignos } & Adenoma & Simples & 6 \\
\hline & & Papilífero & 2 \\
\hline & & Folicular & 1 \\
\hline & & Complexo & 1 \\
\hline & Cistoadenoma & Papilífero & 3 \\
\hline & Misto Benigno & & 8 \\
\hline & Mioepitelioma Benigno & & 1 \\
\hline Total & & & 85 \\
\hline
\end{tabular}

As neoplasias envolveram com maior freqüência os três últimos pares de mamas. os três primeiros pares de mama possuem menor concentração de receptores hormonais, acarretando uma menor probabilidade de desenvolvimento de neoplasias [3].

$\mathrm{Na}$ grande maioria dos pacientes analisados, as lesões tumorais se constituíram de nódulos múltiplos. Diferentes autores encontraram predomínio de nódulos únicos [10] ou múltiplos [1,11].

Neste estudo, quase a totalidade das cadelas analisadas não foram castradas antes do diagnóstico do tumor de mama, além disso, não houve registro de neoplasias em cadelas castradas antes da puberdade. Estes dados não permitiram uma avaliação do efeito protetor da ovariectomia sobre o desenvolvimento das neoplasias mamárias.

Apenas 23,8\% das cadelas com tumor de mama receberam mais do que três aplicações de progestágenos. O uso de progestágenos foi relacionado neste trabalho a uma maior ocorrência de tumores benignos. O papel dos progestágenos como indutores de tumores de mama ainda é controverso. Após tratamentos prolongados com progestágenos, existe relato de aumento na incidência de tumor de mama benigno em cães [16], assim como de ausência de diferença na relação entre tumores benignos e malignos mas com aumento, dose-dependente, de tumores de mama, além de apresentarem tumores mais precocemente [10]. O 
uso de progestágeno provoca aumento leve mas significativo nos tumores de mama, agindo mais sobre o crescimento de lesões subclínicas do que sobre a formação de novas lesões [2].

Pseudocieses foram relatadas em $48 \%$ das cadelas com tumor de mama. Nestes, foi observada uma taxa mais alta de malignidade. Um leve aumento, não significativo, de tumor de mama em cadelas com antecedentes de pseudociese, sem diferença quanto a lesões malignas ou benignas foi observado na literatura [2]. Por outro lado, também é sugerido por outros autores [12] que a pseudociese não tenha efeito no desenvolvimento de tumores de mama.

\section{CONCLUSÃO}

Após analisar os dados de 85 cadelas com neoplasias mamárias, conclui-se que $71,8 \%$ são malignas. Entre as malignas, a mais freqüente é o carcinoma e, entre as benignas, o adenoma. A média de idade é de 9 anos para as neoplasias benignas e 10,2 anos para as malignas. Os progestágenos são relacionados a um maior número de tumores benignos. As pseudocieses são mais relacionadas a tumores de mama malignos. $\mathrm{O}$ uso de progestágenos e o desenvolvimento de pseudocieses são responsáveis pelo aparecimento precoce de tumores de mama em cadelas.

\section{REFERÊNCIAS}

1 Daleck C.R., Franceschini P.H., Alessi A.C., Santana A.E. \& Martins M.I.M. 1998. Aspectos clínico e cirúrgico do tumor mamário canino. Ciência Rural. 28: 95-100.

2 Donnay I., Rauis J. \& Verstegen J. 1994. Influence des antécédents hormonaux sur l'apparition clinique des tumeurs mammaires chez la chienne. Étude épidémiologique. Annales de Médecine Vétérinaire. 138: 109-117.

3 Donnay I., Rauis J., Devleeschouwer N., Wouters-Ballman P., Leclercq G. \& Verstegen J. 1995. Comparison of estrogen and progesterone receptor expression in normal ant tumor mammary tissues from dogs. American Journal of Veterinary Research. 56: 1188-1194.

4 Faustino A.M.R., Van Garderen E., Schalken J.A. \& Nederbragt H. 2002. Tenascin expression in normal, hyperplastic, dysplastic and neoplastic canine mammary tissues. Journal of Comparative Pathology. 126: 1-8.

5 Ferreira G.A., Pedraza F.O. \& Arango M.R. 1997. Neoplasias de glandula mamaria canina diagnosticadas em Medellín, Colombia, entre 1968 e 1994. Veterinaria México. 28: 257-259.

6 Gilbertson S.R., Kurzman I.D., Zachrau R.E., Hurvitz A.I. \& Black M.M. 1983. Canine mammary epithelial neoplasms: biologic implications of morphologic characteristics assessed in 232 dogs. Veterinary Pathology. 20: 127-142.

7 Johnston S.D. 1993. Reproductive systems. In: Slatter D. (Ed). Textbook of Small Animal Surgery. 2nd edn. Philadelphia: Saunders, pp. 2177-2199.

8 Karayannopoulou M., Kaldrimidou E. \& Dessiris, A. 1990. Some epidemiological aspects of canine mammary tumours treatment and prognosis. European Journal of Companion Animal Practice. 1: 41-47.

9 Miranda M. \& Debenedetti R. 1980. Presentacion de diferentes tumores en caninos y felinos de la ciudad de Buenos Aires. Revista Militar de Veterinaria. 26: 197-205.

10 Misdorp W. 1988. Canine mammary tumours: protective effect of late ovariectomy and stimulating effect of progestins. Veterinary Quarterly. 10: 26-33.

11 Misdorp W. 2002. Tumors of the mammary gland. In: Meuten D.J. (Ed). Tumors in domestic dogs. Iowa: Iowa State Press, pp. 575-606.

12 Morris J.S., Dobson J.M., Bostock D.E. \& O'Farrell E. 1998. Effect of ovariohysterectomy in bitches with mammary neoplasms. Veterinary Record. 142: 656-658.

13 Morrisson W.B. 1998. Canine and feline mammary tumors. In: Morrisson W.B. (Ed). Cancer in dogs and cats - medical and surgical management. Baltimore: Williams \& Wilkins, pp. 591-598.

14 O’Keefe D.A. 1997. Tumores do sistema genital e das glândulas mamárias. In: Ettinger S.J. \& Feldman E.C. (Eds). Tratado de Medicina Interna Veterinária. 4 ed. São Paulo: Manole, pp. 2344-2354.

15 Prophet E.B., Mills B. \& Arrington J.B. 1992. Laboratory methods in histotechnology. Washington: Armed Forces Institute of Pathology. American Registry of Pathology, 279p. 
Oliveira L.O., Oliveira R.T., Loretti A.P., Rodrigues R. \& Driemeier D. 2003. Aspectos epidemiológicos da neoplasia mamária canina. Acta Scientiae Veterinariae. 31: 105-110.

16 Selman P.J., Van Garderen E., Mol J.A. \& Van Den Ingh T.S.G.A.M. 1995. Comparison of the histological changes in the dog after treatment with the progestins medroxyprogesterone acetate and proligestone. Veterinary Quarterly. 17: 128-133.

17 Yamagami T., Kobayashi T., Takahashi K. \& Sugiyama M. 1996. Influence of ovariectomy at the time of mastectomy on the prognosis for canine malignant mammary tumours. Journal of Small Animal Practice. 37: 462-464. 